\title{
Docosahexaenoic acid (DHA) in stroke, Alzheimer's disease, and blinding retinal degenerations: coping with neuroinflammation and sustaining cell survival
}

\author{
Nicolas G. BAZAN \\ Aram ASATRYAN \\ Neuroscience Center of Excellence, \\ LSU Health Sciences Center, \\ 2020 Gravier Street, \\ Suite $D$, \\ New Orleans, \\ $L A$, \\ 70112, \\ USA \\ $<$ nbazan@|suhsc.edu $>$
}

\begin{abstract}
The significance of the selective enrichment in omega-3 essential fatty acids in the nervous system has remained, until recently, incompletely understood. While studying mechanisms of cell survival in neurodegenerations, a new docosanoid synthesized from docosahexaenoic acid [DHA] by 15-lipoxygenase-1 [15-LOX-1] was discovered. This mediator, called neuroprotectin D1 [NPD1], is a docosanoid because it is derived from a 22C precursor (DHA), unlike eicosanoids, which are derived from the 20 $C$ arachidonic acid family member of essential fatty acids not enriched in the nervous system. NPD1 is promptly made in response to oxidative stress and brain ischemiareperfusion and in the presence of neurotrophins. NPD1 is neuroprotective in experimental brain damage, oxidative-stressed retinal pigment epithelial [RPE] cells, and in human brain cells exposed to amyloid- $\beta$ peptide. Thus NPD1 is a protective sentinel, one of the very first defenses activated when cell homeostasis is threatened by neurodegenerations. This review highlights the specificity and potency of NPD1 spanning beneficial bioactivity in experimental models of stroke, in retinal cells relevant to early events in age-related macular degenerations, and studies addressing fundamental issues during initiation and early progression of neurodegenerations.
\end{abstract}

Key words: ischemia-reperfusion, neuroprotectin D1, docosanoids, retinal pigment epithelial cells, photoreceptors

discovery of a DHA-derived docosanoid called neuroprotectin D1 [NPD1,10R, 17S-dihydroxy-docosa-4Z, 7Z, 11E, 13E, $15 E, 19 Z$ hexaenoic acid]. As a docosanoid, NPD1 is derived from a 22C precursor of the essential fatty acids that are not enriched in the nervous system (see figure 1 for an illustration of NPD1 biosynthesis). NPD1 is made in response to oxidative stress and brain ischemiareperfusion and is neuroprotective in experimental brain damage, oxidativestressed retinal pigment epithelial [RPE] cells, and in human brain cells exposed to amyloid- $\beta$ peptide. Essentially, NPD1 is a protective sentinel, one of the very first defenses activated when cell homeostasis is threatened by injury or neurodegenerations. We highlight here the knowledge gained from basic research approaches regarding the specificity and potency of the lipid mediator NPD1, spanning beneficial bioactivity during initiation and early progression of retinal degenerations, ischemic stroke, Alzheimer's disease, and other neurodegenerations.

\section{Retinal degenerations}

Photoreceptors renew membrane disks, which contain the phototransduction apparatus and phospholipids rich in DHA, intermittently via shedding of their tips and phagocytosis by RPE cells. At the same time, new membrane disks are made at the base of the outer segments; their length remains constant and cell integrity is maintained remarkably

To cite this article: Bazan NG, Asatryan A. Docosahexaenoic acid (DHA) in stroke, Alzheimer's disease, and blinding retinal degenerations: coping with neuroinflammation and sustaining cell survival. OCL 2011; 18(4): 208-13. doi : 10.1684/ocl.2011.0403 


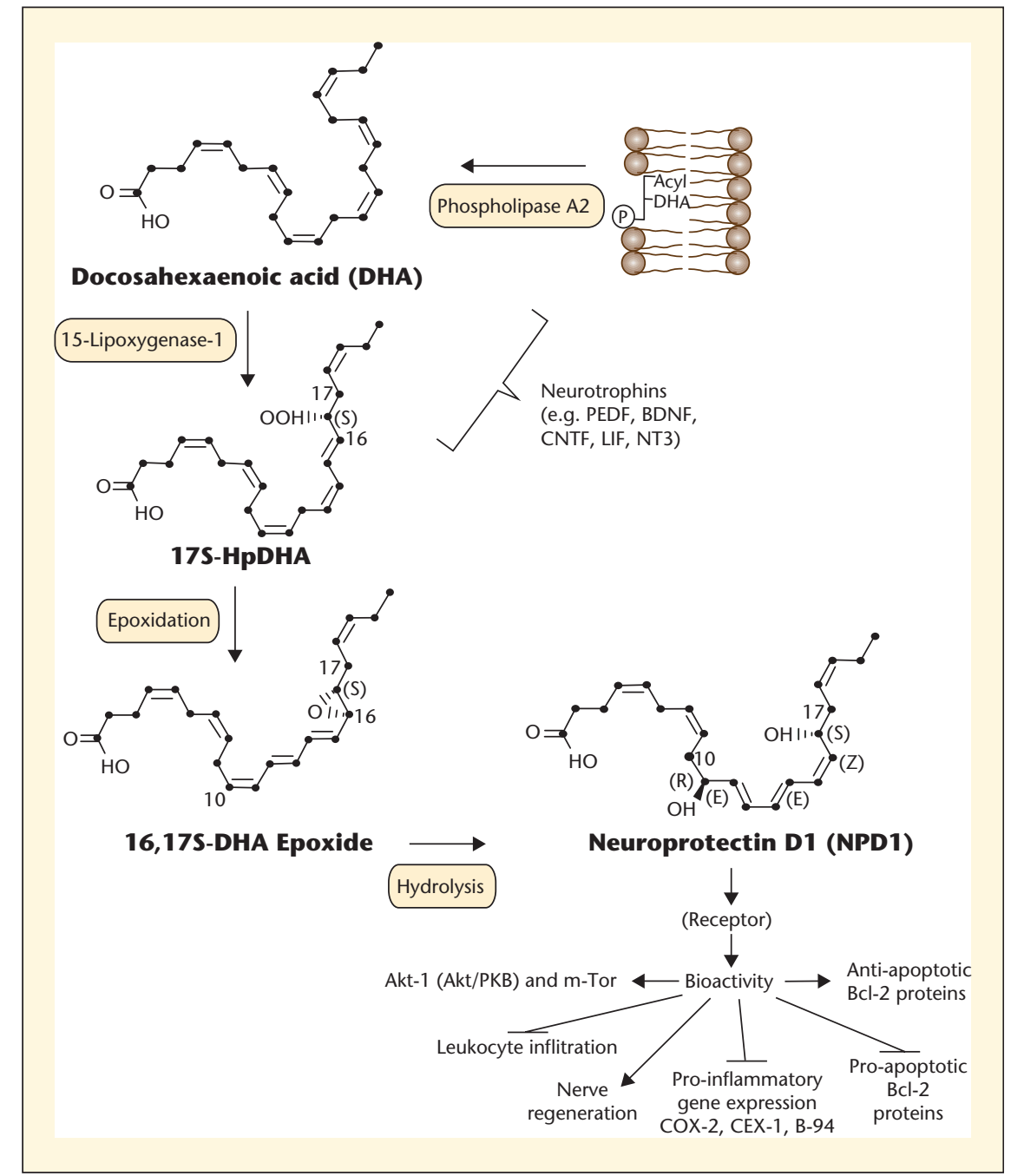

Figure 1. Biosynthesis of neuroprotectin D1 [NPD1]. A membrane phospholipid containing a docosahexaenoyl chain at sn-2 is hydrolyzed by phospholipase A2, generating free (unesterified) docosahexaenoic acid [DHA] (22:6). Lipoxygenation (Calandria et al., 2009) is then followed by epoxidation and hydrolysis to generate NPD1. Thus far, a binding site for NPD1 has been identified in retinal pigment epithelial cells and polymorphonuclear cells. Modified, with permission, from the Annual Review of Nutrition, Volume 31(C) 2011 by Annual Reviews www. annualreviews.org

unchanged throughout many decades. This outcome occurs in spite of the fact that the photoreceptors are in an oxidative stress-prone environment (light, high $\mathrm{O}_{2}$ consumption, high polyunsaturated fatty acid fluxes, etc.). Phagocytosis of photoreceptor disks promotes, via NPD1 synthesis, specific refractoriness to oxidative stress-induced apoptosis in RPE cells, which in turn fosters homeostatic photoreceptor cell integrity (Mukherjee et al., 2007a,b). Disruptions of the sentinel role of NPD1 during photoreceptor renewal may participate in macular degeneration and other retinal degenerations leading to blind- which includes the cellular organization of DHA uptake, its distribution among cellular compartments, the organization and function of membrane domains rich in DHA-containing phospholipids, and the signaling pathways regulated by DHA and NPD1 (Bazan et al., 2011). Neurotrophins are active NPD1 synthesis agonists (Mukherjee et al., 2007a) (figure 1).

\section{Stroke}

Focal cerebral ischemia injures the brain core and damages the penumbra. The penumbra can be rescued potentially (Fisher, 2006), but it undergoes damage after a few hours unless reperfusion is initiated (Lo, 2008).

In brain ischemia-reperfusion, DHA (i.v.) one hour after two hours of middle cerebral artery occlusion [MCAO] leads to penumbra protection with an extended time window of protection (up to five hours) and with concomitant NPD1 synthesis (Belayev et al., 2011). Anti-apoptotic, BCL-2 protein family availability is positively modulated by NPD1, whereas pro-apoptotic BCL-2 proteins are negatively regulated, as is the arrival of leukocytes due to neurovascular unit breakdown.

Recently low- and medium-dose DHA therapy has been shown to improve neurological and histological outcomes after focal cerebral ischemia (Belayev et al., 2009). Non-invasive magnetic resonance imaging [MRI] and mass spectrometry, in conjunction with behavioral, histological and immunostaining methods, were used to provide evidence for $\mathrm{DHA}$ protection of the ischemic penumbra (Belayev et al., 2011).

Neuroprotection is thought to defend neurons from the ischemia-induced neurotoxic environment, however the complex processes that occur after stroke require targeting of multiple factors and cells, including glia, vascular and inflammatory cells. The distribution of molecular markers in the infarcted regions of the DHA-treated brain indicate that treatment with DHA protects not only the neurons, but also astrocytes, which are critical for neuronal maintenance and protection via secretion of growth factors and other neurotrophic mediators. Furthermore, DHA attenuates microglia activation resulting from cellular damage and reduces the inflammatory response that normally 


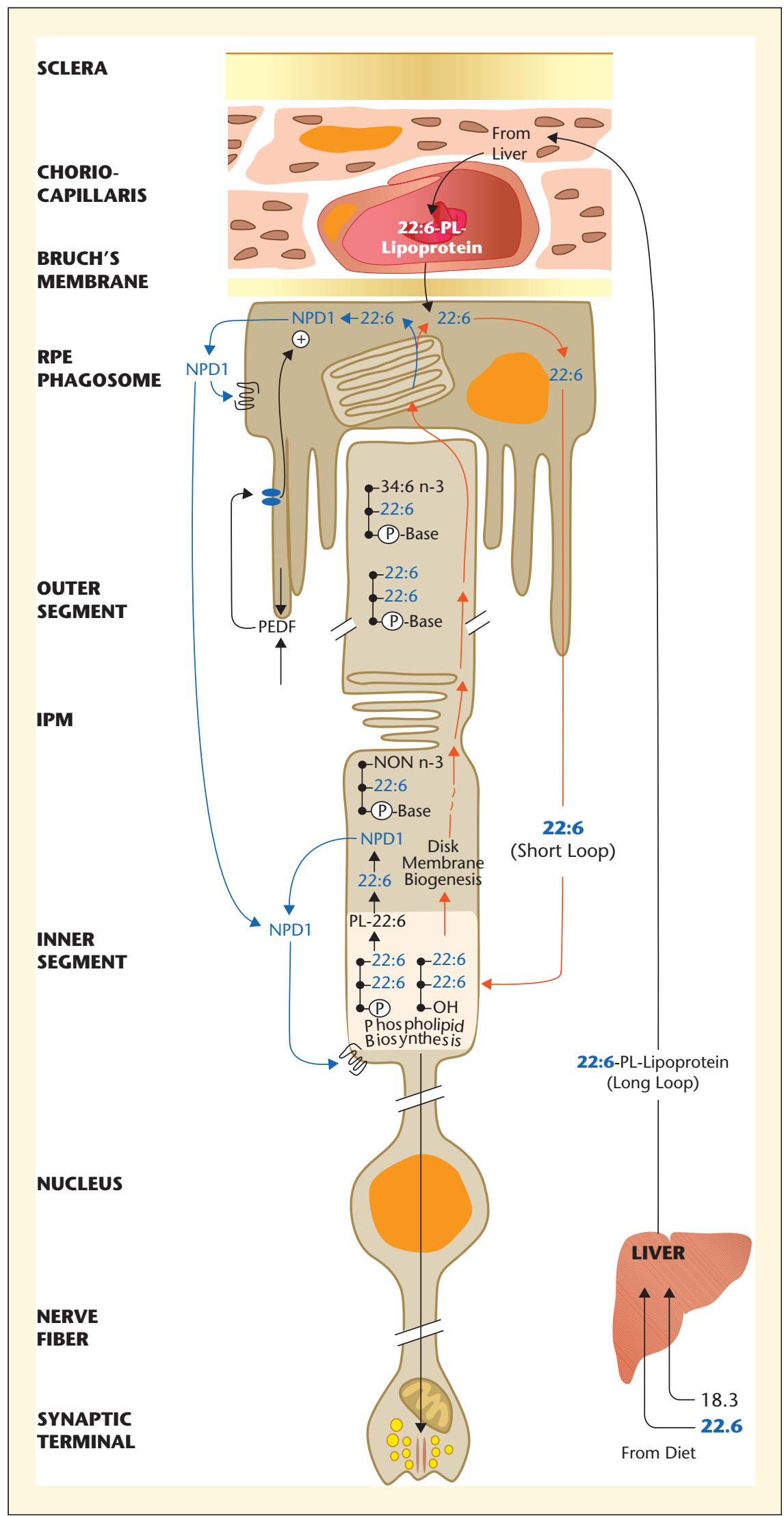

Figure 2. Docosahexaenoic acid [DHA] (22:6) delivery to photoreceptors from the liver. leads to apoptosis and debris removal. This demonstrates the anti-inflammatory properties of DHA during cellular stress (Belayev et al., 2011).

DHA treatment activates NPD1 synthesis in the salvageable penumbral region. NPD1 is a potent lipid mediator that evokes counteracting cell-protective, anti-inflammatory, pro-survival repair signaling, including the induction of anti-apoptotic proteins and inhibition of pro-apoptotic proteins (Belayev et al., 2011). NPD1 triggers activation of signaling pathway/s that modulate/s pro-apoptotic signals, enhancing cell survival in the ischemic stroke-damaged penumbra (Bazan et al., 2010).

\section{Alzheimer's disease}

Alzheimer's disease [AD] is a multifactorial, complex neurodegeneration characterized by progressive cognitive impairment. It involves a beta amyloid precursor protein [ $\beta A P P]$ processing dysfunction that leads to increased 42 amino acid $A \beta 42$ peptide oligomer, which in turn impairs synaptic function and, progressively, synaptic circuits. Also, intracellular neurofibrillary tangles are formed, and neuroinflammation is enhanced, leading to apoptosis.

NPD1 is drastically reduced in hippocampal cornu ammonis 1 [CA1] areas of Alzheimer's patients. Thus, NPD1 recapitulates part of the Alzheimer's pathology in cellular models. Human neurons and astrocytes challenged by amyloid- $\beta$ $[A \beta]$ or by overexpressing APPsw (double Swedish mutation) show that NPD1 downregulates amyloidogenic processing of amyloid- $\beta$ precursor protein, switches off pro-inflammatory gene expression (cyclooxygenase-2, tumor necrosis factor alpha, and B-94-TNF- $\alpha$ inducible pro-inflammatory element), and promotes neural cell survival. Moreover, anti-amyloidogenic processing by NPD1 targets $\alpha$ - and $\beta$-secretases and peroxisome proliferator-activated receptor gamma [PPAR $\gamma$ ] receptor activation. The apoptotic cascade involves multiple checkpoints and signaling networks. NPD1 regulation targets upstream events of apoptosis as well as neuroinflammatory signaling, in turn promoting homeostatic regulation of cell integrity.

The oligomer $A \beta 42$ accumulates as an aggregate and becomes a component 
of senile plaques (Bertram et al., 2010; Goedert et al., 2010; Golde et al., 2006; Haass, 2010; Haass and Selkoe, 2007; Haass and Mandelkow, 2010). A $\beta 42$ peptides are generated from $\beta A P P$ via tandem cleavage by $\beta$ - and $\gamma$-secretases. Alternatively, a second pathway may be activated through $\alpha$-secretase distintegrin and metalloproteinase 10 [ADAM10] that cleaves $\beta A P P$ to yield soluble amyloid precursor protein alpha $(\mathrm{sAPP} \alpha)$ (neurotrophic or nonamyloidogenic pathway).

The central nervous system [CNS] response to injury, and to the onset and progression of neurodegeneration, involves the release of free DHA and arachidonic acid [AA] along with the synthesis of stereospecific docosanoid derivatives. Human neural [HN] progenitor cells in primary culture during eight weeks display an eightfoldenhanced synthesis and release of $A \beta 40$ and $A \beta 42$ peptides that resembles $A \beta$ deposition during brain aging and in $A D$. In HN cells, $A \beta 42$ triggers damaging signals (accompanied by the early onset of apoptosis) and changes in gene expression that emulate neurodegenerative events characteristic of $\mathrm{AD}$. DHA partially counteracts cognitive decline in the elderly (Fotuhi et al., 2009). Moreover, omega-3 essential fatty acid-rich diets are associated with a trend in reduced risk for mild cognitive impairment $[\mathrm{MCl}]$ and with $\mathrm{MCl}$ conversion to $A D$, whereas DHA has been shown to be beneficial in transgenic $A D$ models (Akbar et al., 2005; Fotuhi et al., 2009; Green et al., 2007; Lim et al., 2005a; Salem et al., 2001). The DHAderived NPD1 displays neuroprotective bioactivity in brain and retinal cells against various insults, including oxidative injury, ischemia-reperfusion, and inflammation (Antony et al., 2010; Li et al., 2001; Lim et al., 2005b; Moore, 2001; Salem et al., 2001). The AD brain (Lukiw et al., 2005) exhibits reductions in DHA and NPD1. We further characterized the anti-inflammatory and antiapoptotic activity of NPD1 in cocultures of $\mathrm{HN}$ cells stressed with the $\mathrm{A} \beta 42$ oligomer, and studied the NPD1-mediated modulation of $\alpha$ - and $\beta$-secretase activity that resulted in reduced shedding of A 442 (Zhao et al., 2011).

The hippocampal CA1 region, the area of cortex most heavily damaged by $A D$, displays one-twentieth of the NPD1 of age-matched controls, even though the difference in free DHA was only two-fold lower; these changes were not present in other brain regions (Lukiw et al., 2005). Potent protective bioactivity of NPD1 was shown in various models of neuroinflammatory pathology, including age-related macular degeneration [AMD] (Bazan, 2006, Bazan, 2007; Mukherjee et al., 2004), stroke (Bazan, 2003; d'Abramo et al., 2005; Lim et al., 2005b), epilepsy (Bazan, 2007), AD (Bazan, 2009; DeMar et al., 2006; Lukiw et al., 2005), and oxidative stress (Lukiw et al., 2005; Marcheselli et al., 2003; Mukherjee et al., 2004). These observations implicate NPD1 as an integral homeostatic modulator of long-term function and highlight the needs of DHA accretion in the CNS.

\section{Neuroinflammatory signaling}

Neuroinflammatory signaling associated with $A \beta 42$ is an important contributor to the pathology of neurodegenerations (Amor et al., 2010; Walsh and Selkoe, 2007). While glial cells provide some neuroprotective "shielding" when exposed to $A \beta 42$, both neuronal and glial cells release cytokines that activate more microglia and astrocytes and reinforce pathogenic signaling. In HN cell models of $A \beta 42$ toxicity, microarray and Western blot analysis revealed down-regulation of proinflammatory genes (cyclooxygenase-2, tumor necrosis factor alpha, and B94), suggesting that the anti-inflammatory bioactivity of the neuroprotective lipid mediator NPD1 partially targets this gene family (Lukiw et al., 2005) and that these effects are persistent up to 12 hours after treatment by A 342 and NPD1 (Zhao et al., 2011).

Studies show, however, that NPD1 had no effect on PS1 levels in primary human glial [HG] cells, but rather a significant increase in ADAM10 occurred in conjunction with a decrease in beta-site amyloid precursor proteincleaving enzyme 1 ( $\beta$-secretase- 1$)$ [BACE1]. NPD1 reduced $A \beta 42$ levels released from $\mathrm{HN}$ cells, and examination of other $\beta A P P$ fragments revealed that after NPD1 addition, levels of $\beta A P P$ expression remained unchanged. Hence this indicates a shift by NPD1 in $\beta A P P$ processing from the amyloidogenic to nonamyloidogenic pathway. NPD1 further down-regulated BACE1 and activated ADAM10, a putative $\alpha$ secretase. ADAM10 siRNA knockdown and BACE1 overexpression-activity experiments confirmed that both are required in NPD1's regulation of $\beta A P P$. Therefore, NPD1 appears to function favorably in both of these competing $\beta$ APP-processing events.

In addition, PPAR $\gamma$ activation leads to anti-inflammatory, anti-amyloidogenic actions and anti-apoptotic bioactivity, as does NPD1. Some fatty acids are natural ligands for PPAR $\gamma$, which has a predilection for binding polyunsaturated fatty acids (Camacho et al., 2004; d'Abramo et al., 2005; Henke, 2004). NPD1 is a PPAR $\gamma$ activator, as shown by using both human adipogenesis and cellbased-transactivation assay (Zhao et al., 2011). NPD1 may activate PPAR $\gamma$ via direct binding or other interactive mechanisms (Avramovich et al., 2002; Yamamoto et al., 2005). Analysis of BAPPderived fragments revealed that PPAR $\gamma$ does play a role in the NPD1-mediated suppression of $A \beta$ production. Activation of PPAR $\gamma$ signaling is further confirmed by the observation that PPAR $\gamma$ activity decreases BACE1 levels, and a PPAR $\gamma$ antagonist overturns this decrease. Thus, 
the antiamyloidogenic bioactivity of NPD1 is associated with activation of the PPAR $\gamma$ and the subsequent BACE1 downregulation. The decreases in BACE1 may be the cause for $A \beta$ reduction (Sastre et al., 2006; Zhao et al., 2011).

There is evidence that DHA initiates a cascade of mediators, where NPD1 is the first identified. NPD1 is endowed with strong anti-inflammatory, antiamyloidogenic, and anti-apoptotic bioactivities. These results suggest that the anti-amyloidogenic effects of NPD1 are mediated in part through activation of the PPAR $\gamma$ receptor, whereas NPD1 stimulation of nonamyloidogenic pathways is PPAR $\gamma$ independent (Zhao et al., 2011). NPD1 stimulation of ADAM10, coupled to suppression of BACE1-mediated $A \beta 42$ secretion, clearly warrants further study since these dual secretasemediated pathways may provide effective combinatorial or multi-target approaches in the clinical management of the neuroinflammatory process.

\section{Conclusion}

The further unraveling of the DHA signalolipidome will contribute to harnessing the endogenous homeostatic signaling that counter-regulates neuroinflammation, and thus sustain cell integrity by downregulating apoptotic cell death.

Acknowledgements. This work was supported by NIH: NINDS R01 NS046741, NEI R01 EY005121, NCCAM RC2 AT005909, NCRR P20 RR016816, the American Health Assistance Foundation and the National Foundation Fighting Blindness.

\section{REFERENCES}

Akbar M, Calderon F, Wen Z, Kim H. Docosahexaenoic acid: a positive modulator of Akt signaling in neuronal survival. Proc Natl Acad Sci USA 2005; 102: 10858-63.

Amor S, Puentes F, Baker D, van der Valk P. Inflammation in neurodegenerative diseases. Immunology 2010; 129: 154-69.

Antony R, Lukiw WJ, Bazan NG. Neuroprotectin D1 induces dephosphorylation of $\mathrm{BCl}-\mathrm{xL}$ in a PP2A-dependent manner during oxidative stress and promotes retinal pigment epithelial cell survival. J Biol Chem 2010; 285: 18301-8.

Avramovich Y, Amit T, Youdim MB. Nonsteroidal anti-inflammatory drugs stimulate secretion of non-amyloidogenic precursor protein. J Biol Chem 2002; 277: 31466-73.

Bazan NG. Synaptic lipid signaling: significance of polyunsaturated fatty acids and platelet-activating factor. J Lipid Res 2003; 44: 2221-33.

Bazan NG. Cell survival matters: docosahexaenoic acid signaling, neuroprotection and photoreceptors. Trends Neurosci 2006; 29: 241-94.

Bazan NG. Homeostatic regulation of photoreceptor cell integrity: Significance of the potent mediator neuroprotectin D1 biosynthesized from docosahexaenoic acid. The Proctor Lecture. Invest Ophthal Vis Sci 2007; 48: 4866-81.

Bazan NG. Neuroprotectin D1-mediated anti-inflammatory and survival signaling in stroke, retinal degenerations, and Alzheimer's disease. J Lipid Res 2009; 50: S400-5.

Bazan NG, Calandria JM, Serhan CN. Rescue and repair during photoreceptor cell renewal mediated by docosahexaenoic acid-derived neuroprotectin D1. J Lipid Res 2010; 51: 2018-31.

Bazan NG, Molina MF, Gordon WC. Docosahexaenoic Acid signalolipidomics in nutrition: significance in aging, neuroinflammation, macular degeneration, Alzheimer's, and other neurodegenerative diseases. Annu Rev Nutr 2011; 31: 321-51.

Belayev L, Khoutorova L, Atkins KD, Bazan NG. Robust docosahexaenoic acid-mediated neuroprotection in a rat model of transient focal cerebral ischemia. Stroke 2009; 40: 3121-6.

Belayev L, Khoutorova L, Atkins KD, et al. Docosahexaenoic acid therapy of experimental ischemic stroke. Trans/ Stroke Res 2011; 2: 33-41.

Bertram L, Lill CM, Tanzi RE. The genetics of Alzheimer disease: back to the future. Neuron 2010; 68: 270-81.

Calandria JM, Marcheselli VL, Mukherjee PK, et al. Selective survival rescue in 15-lipoxygenase- 1 deficient retinal pigment epithelial cells by the novel docosahexaenoic acid-derived mediator, neuroprotectin D1. J Biol Chem 2009; 284: 17877-82.

Camacho IE, Serneels L, Spittaels K, Merchiers P, Dominguez D, De Strooper B. Peroxisomeproliferator-activated receptor gamma induces a clearance mechanism for the amyloidbeta peptide. I Neurosci 2004; 24: 10908-17.

d'Abramo C, Massone S, Zingg JM, et al. Role of peroxisome proliferator-activated receptor gamma in amyloid precursor protein processing and amyloid beta-mediated cell death. Biochem / 2005; 391: 693-8.

DeMar JCJr, Ma K, Bell JM, Igarashi M, Greenstein D, Rapoport SI. One generation of $n-3$ polyunsaturated fatty acid deprivation increases depression and aggression test scores in rats. J Lipid Res 2006; 47: 172-80.

Fisher M. The ischemic penumbra. Cerebrovasc Dis 2006; 21: 64-70.

Fotuhi M, Mohassel P, Yaffe K. Fish consumption, long-chain omega-3 fatty acids and risk of cognitive decline or Alzheimer disease: a complex association. Nat Clin Pract Neurol 2009; 5: 140-52.

Goedert M, Clavaguera F, Tolnay M. The propagation of prion-like protein inclusions in neurodegenerative diseases. Trends Neurosci 2010; 33: 317-25.

Golde TE, Dickson D, Hutton M. Filling the gaps in the abeta cascade hypothesis of Alzheimer's disease. Curr Alzheimer Res 2006; 3: 421-30.

Green KN, Martinez-Coria H, Khashwji H, et al. Dietary docosahexaenoic acid and docosapentaenoic acid ameliorate amyloidbeta and tau pathology via a mechanism involving presenilin 1 levels. J Neurosci 2007; 27: 4385-95.

Haass C. 2010. Initiation and propagation of neurodegeneration. Nat Med 2010; 16: 1201-4.

Haass C, Selkoe DJ. Soluble protein oligomers in neurodegeneration: lessons from the Alzheimer's amyloid beta-peptide. Nat Rev Mol Cell Biol 2007; 8: 101-12.

Haass C, Mandelkow E. Fyn-tau-amyloid: a toxic triad. Cell 2010; 142: 356-8.

Henke BR. Peroxisome proliferator-activated receptor gamma (PPARgamma) ligands and their therapeutic utility. Prog Med Chem 2004; 42: 1-53.

Li F, Cao W, Anderson RE. Protection of photoreceptor cells in adult rats from lightinduced degeneration by adaptation to bright cyclic light. Exp Eye Res 2001; 73: 569-77.

Lim SY, Hoshiba J, Moriguchi T, Salem N Jr. $\mathrm{N}-3$ fatty acid deficiency induced by a modified artificial rearing method leads to poorer performance in spatial learning tasks. Pediatr Res 2005a; 58: 741-8.

Lim SY, Hoshiba J, Salem N Jr. An extraordinary degree of structural specificity is required in neural phospholipids for optimal brain function: n-6 docosapentaenoic acid substitution for docosahexaenoic acid leads to a loss in spatial task performance. J Neurochem 2005b; 95: 848-57.

Lo EH. A new penumbra: transitioning from injury into repair after stroke. Nat Med 2008; 14: 497-500.

Lukiw WJ, Cui JG, Marcheselli VL, et al. A role for docosahexaenoic acid-derived neuroprotectin D1 in neural cell survival and Alzheimer disease. J Clin Invest 2005; 115: 2774-83. 
Marcheselli VL, Hong S, Lukiw W], et al. Novel docosanoids inhibit brain ischemia-reperfusion-mediated leukocyte infiltration and proinflammatory gene expression. I Biol Chem 2003; 278: 43807-1.

Moore SA. Polyunsaturated fatty acid synthesis and release by brain-derived cells in vitro. / Mol Neurosci 2001; 16: 195200.

Mukherjee PK, Marcheselli VL, Serhan CN, Bazan NG. Neuroprotectin D1: a docosahexaenoic acid-derived docosatriene protects human retinal pigment epithelial cells from oxidative stress. Proc Natl Acad Sci USA 2004; 101: 8491-6.

Mukherjee PK, Marcheselli VL, Barreiro S, $\mathrm{Hu}$ J, Bok D, Bazan NG. Neurotrophins enhance retinal pigment epithelial cell sur- vival through neuroprotectin D1 signaling. Proc Natl Acad Sci USA 2007a; 104: 13152-7.

Mukherjee PK, Marcheselli VL, de Rivero Vaccari JC, Gordon WC, Jackson FE, Bazan NG. Photoreceptor outer segment phagocytosis attenuates oxidative stress-induced apoptosis with concomitant neuroprotectin D1 synthesis. Proc Natl Acad Sci USA 2007b; 104: 13158-63.

Salem N, Litman B, Kim HY, Gawrisch K. Mechanisms of action of docosahexaenoic acid in the nervous system. Lipids 2001; 36: 945-59.

Sastre M, Dewachter I, Rossner S, et al. Nonsteroidal anti-inflammatory drugs repress beta-secretase gene promoter activity by the activation of PPARgamma. Proc Natl Acad Sci USA 2006; 103: 443-8.
Serhan CN. Novel lipid mediators and resolution mechanisms in acute inflammation: to resolve or not? Am J Pathol 2010; 177: 1576-91.

Walsh DM, Selkoe DJ. A beta oligomers-a decade of discovery. I Neurochem 2007; 101: 1172-84.

Yamamoto K, Itoh T, Abe D, et al. Identification of putative metabolites of docosahexaenoic acid as potent PPARgamma agonists and antidiabetic agents. Bioorg Med Chem Lett 2005; 15: 517-22.

Zhao Y, Calon F, Julien C, et al. Docosahexaenoic acid-derived neuroprotectin D1 induces neuronal survival via secretase- and PPAR $\gamma$-mediated mechanisms in Alzheimer's disease models. PLoS One 2011; 6: e15816. 